\title{
RESEARCH
}

Open Access

\section{Households forgoing healthcare as a measure of financial risk protection: an application to Liberia}

\author{
Jacopo Gabani ${ }^{1,2^{*}}$ (1) and Lorna Guinness ${ }^{2}$
}

\begin{abstract}
Introduction: Access to Liberia's health system is reliant on out-of-pocket (OOP) health expenditures which may prevent people from seeking care or result in catastrophic health expenditure (CHE). CHE and impoverishment due to OOP, which are used by the World Bank and World Health Organization as the sole measures of financial risk protection, are limited: they do not consider households who, following a health shock, do not incur expenditure because they cannot access the healthcare services they need (i.e., households forgoing healthcare (HFH) services). This paper attempts to overcome this limitation and improve financial risk protection by measuring HFH incidence and comparing it with CHE standard measures using household survey data from Liberia.

Methods: Data from the Liberia Household Income and Expenditure Survey 2014 were analysed. An OOP health expenditure is catastrophic when it exceeds a total or non-food household expenditure threshold. A CHE incidence curve, representing CHE incidence at different thresholds, was developed. To overcome CHE limitations, an HFH incidence measure was developed based on $\mathrm{CHE}$, OOP and health shocks data: households incurring health shocks and having negligible OOP were considered to have forgone healthcare. HFH incidence was compared with standard CHE measures.
\end{abstract}

Results: CHE incidence and intensity levels depend on the threshold used. Using a 30\% non-food expenditure threshold, CHE incidence is $2.1 \%$ (95\% Cl: 1.7-2.5\%) and CHE intensity is 37.4\% (95\% Cl: 22.7-52.0\%). CHE incidence is approximately in line with other countries, while CHE intensity is higher than in other countries. CHE pushed $1.6 \%$ of households below the food poverty line in 2014. HFH incidence is approximately 4 times higher than CHE (8.0, 95\% Cl, 7.2-8.9\%).

Conclusion: Lack of financial risk protection is a significant problem in Liberia and it may be underestimated by CHE: this study confirms that HFH incidence can complement CHE measures in providing a complete picture of financial risk protection and demonstrates a simple method that includes measures of healthcare forgone as part of standard CHE analyses. This paper provides a new methodology to measure HFH incidence and highlights the need to consider healthcare forgone in analyses of financial risk protection, as well as the need for further development of these measures.

Keywords: Health financing, Equity, Liberia, Impoverishment, Catastrophic health expenditure, Forgoing healthcare, Financial risk protection

\footnotetext{
* Correspondence: jg1671@york.ac.uk

${ }^{1}$ Centre for Health Economics, University of York, York, UK

${ }^{2}$ London School of Hygiene \& Tropical Medicine, London, UK
} 


\section{Key messages}

- Catastrophic Health Expenditures (CHE) and impoverishment effect of out-of-pocket (OOP) health expenditure do not fully represent financial risk protection as people forgoing healthcare are excluded from those measures

- CHE are incurred by 0.4 to $2.1 \%$ of households in Liberia, and they are more concentrated in poorer households than in richer households, and $1.6 \%$ of households have been pushed into poverty in 2014 by OOP health expenditure in Liberia

- However, an even greater number of households are estimated to forgo healthcare in Liberia (8.0\%)

- Omitting a measure of households forgoing healthcare from financial risk protection measures under-estimates the full extent of financial barriers to healthcare on poorer households in Liberia

- Research on households forgoing healthcare should be included in standard financial risk protection measurement to capture the potential gains from universal healthcare coverage.

\section{Introduction}

Universal Health Coverage (UHC) is defined as "ensuring that all people have access to needed healthcare services of sufficient quality to be effective while also ensuring that the use of these services does not expose the user to financial hardship" [40]. Across the globe, UHC and countries' progress towards it have received increased attention since its inclusion in the Sustainable Development Goals [28]. However, measures of progress towards UHC are complex as they need to consider both the degree of financial risk protection [23] that is achieved as well as changes in service coverage [5]. The global UHC framework for monitoring progress developed by the World Bank and WHO captures these concepts through a multi-dimensional framework, taking into account the services that are covered, who is covered and the degree to which the population access pooled funds and achieve financial protection $[5,32]$. In examining financial protection, this includes two indicators: catastrophic health expenditure (CHE) and the impoverishing effect of out-of-pocket (OOP) health expenditure, both of which should be presented in the aggregate and broken down by socioeconomic group in order to capture the distributional impact of healthcare spending $[5,23]$.

CHE are said to occur when out-of-pocket expenditures as a share of household resources surpasses a given threshold [20,31]. The thresholds used in CHE analysis are designed to reflect a household's capacity to pay which can be defined by household income, consumption expenditure or non-food consumption expenditure, depending on the data available and the analyst's approach $[18,20,41]$. In the case of the impoverishing effect of OOP health expenditure, the threshold describes a poverty line defined at a national or international level [20,31]. In both cases, the aggregate form addresses the issue of horizontal equity (i.e. people with similar income contribute in similar ways to health system financing [22]); whereas the distribution by socioeconomic group helps us understand the degree to which vertical equity (i.e. wealthier people contribute more than poorer people to health system financing [22]) is being addressed or may need to be addressed.

These indicators have succeeded in providing a useful starting point for measuring progress related to financial protection under UHC. Yet both measures suffer from limitations in their ability to capture the full impact of healthcare need on household resources. The arbitrariness related to choosing the threshold makes it difficult to compare across different analyses [11, 27]). Hsu et al. [11] have addressed this by using a "CHE incidence curve" which can provide meaningful cross-country comparisons [11]. A further criticism of $\mathrm{CHE}$ and the impoverishing effect of OOP as measures of progress in financial protection is that they only consider the effects of an expenditure [7, 18]; households who suffer financial hardship because they cannot afford, or access, healthcare would not be counted. Therefore, CHE and impoverishing expenditure are likely to under-estimate the number of people without financial risk protection. This potential for under-estimation is a problem in countries with high inequality or a large proportion of the population living below the poverty line [21].

As yet, measures for identifying and counting these missing populations are not used in measuring financial risk protection [17] and monitoring UHC [1], leading to unexpected results regarding financial risk protection. According to the "Tracking UHC, Global Monitoring Report" [32], low-income countries populations are more financially protected than middle- and high-income countries populations; such counter-intuitive findings may be driven by the under-estimation of financial risk protection that is implied in CHE and impoverishment measures (Fig. 1).

Liberia is a low-income country where years of conflict have damaged the health system [12]. In 2015, its GDP per capita was the 7th lowest globally, approximately $35 \%$ below the average for low-income countries [33]. Health status measures also showed a challenging situation: Liberia's maternal mortality rate and under- 5 mortality rate were respectively 11th and 26th highest globally, approximately 40 and 5\% higher than the average for low-income countries [34, 35]. Out-of-pocket health expenditures in Liberia make up $19.6 \%$ of total health expenditure in 2015 [39], the percentage of 


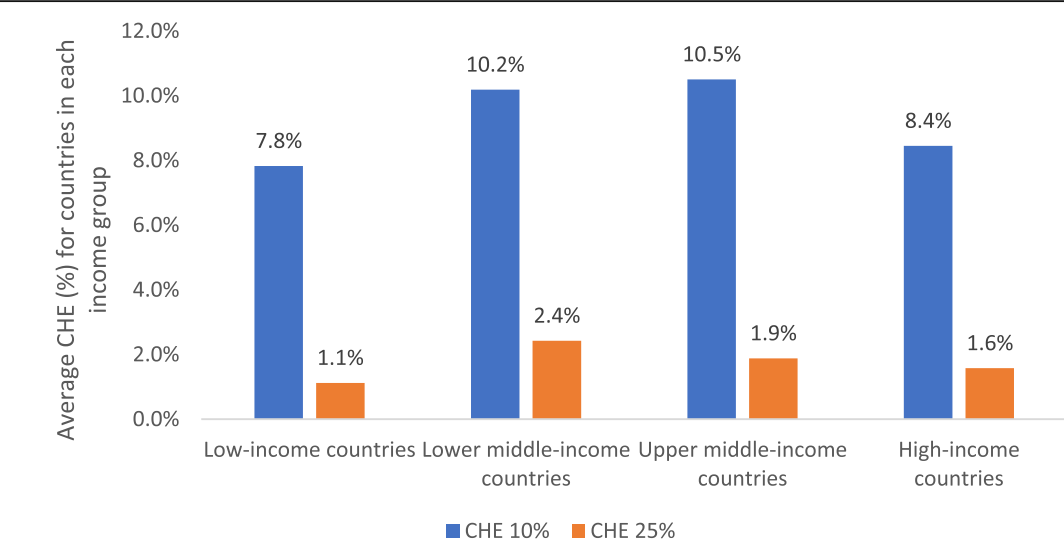

Source: author elaboration based on "Tracking UHC, Global Monitoring Report" (World Bank; World Health Organization, 2017) and World Bank Country and Lending Groups (World Bank, 2018)

Fig. 1 Average Catastrophic Health Expenditure (CHE) of countries depending on their income groups. Source: author elaboration based on "Tracking UHC, Global Monitoring Report" [32] and World Bank Country and Lending Groups [38]

people living below the poverty line is high $(50.9 \%$ in 2016) [15] and there is no recent study of CHE or impoverishing health expenditure. Access to publicly funded services is open to all citizens, and public healthcare services are financed through domestic revenues. However, the Liberian health system is highly reliant on external financing, as $71 \%$ of its total health expenditure is external. Only $7 \%$ of total health expenditure is financed by domestic revenues. The remainder is private health expenditure, which is largely out-of-pocket [39]. This paper explores financial risk associated with healthcare in Liberia and proposes a method to complement financial risk protection measures in the WHO/World Bank global monitoring framework for UHC. Alongside standard catastrophic and impoverishing expenditure analyses, it measures how many households are forgoing healthcare services.

\section{Methods}

\section{Study sample and data}

Liberia is a low-income country in sub-Saharan Africa with 4.7 million people, life expectancy of 63 years, GNI per capita of 620 US\$ [37] and 0.08 physicians per 1000 people [39]. Data analysed in this paper are taken from the Liberia Household Income and Expenditure Survey 2014-2015 (HIES) [15], the first household income and expenditure survey in Liberia since 1964 [15]. Although the Ebola virus (EVD) hit Liberia in 2014 and interrupted the HIES data collection, approximately $50 \%$ of the sample was surveyed so that the data are still representative at the national level [15]. Data required for the analysis of financial risk protection using $\mathrm{CHE}$ and impoverishment indicators include OOP, household consumption expenditure, household capacity to pay and the national poverty line. In addition, asset indices are required to explore the distribution of CHE across income quintiles. Table 1 provides a list of variables used in the analyses as well as their definitions and sources.

\section{Data analysis \\ Catastrophic health expenditure incidence and intensity}

OOP health expenditure was defined as the total household expenditure on formal and informal healthcare over a oneyear period, excluding health insurance contributions. Formal healthcare is defined modern healthcare services provided by regulated facilities (i.e. government facilities, private facilities and NGO-run facilities), while informal healthcare refers to services provided by unlicensed traditional and faith health [26]. The CHE incidence is the number of people whose OOP exceeds the identified threshold in the given period [20,31]. Following the World Bank and World Health Organization [32], OOP were compared with total consumption expenditure, and the standard CHE threshold values varied between 10 and $25 \%$. Capacity to pay (i.e. total non-food consumption expenditure) was also used as a comparator and the thresholds varied between 30 and 40\% [29, 41]. See Appendix 1 for full details of the methods. Given that no "right or wrong" threshold can be defined [11, 20], a sensitivity analysis was performed to show how CHE incidence varies across the CHE threshold values. The sensitivity analysis is graphically presented by plotting CHE incidence curves against the different threshold values [11].

CHE incidence is also not able to capture how much the threshold is exceeded by OOP payments. CHE intensity or overshoot measures how much households incurring $\mathrm{CHE}$ are affected by $\mathrm{CHE}[7,20,31]$. The overshoot for each household was estimated as the difference between the threshold value and the out of pocket expenditure as a proportion of capacity to pay. The average 
Table 1 List of variables, and their definitions, used in the analysis of Catastrophic Health Expenditure and Healthcare Foregone

\begin{tabular}{|c|c|c|c|c|c|c|}
\hline$\#$ & Variable & Definition & $\begin{array}{l}\text { Related } \\
\text { Questions/ } \\
\text { Database } \\
\text { items }\end{array}$ & $\begin{array}{l}\text { Connection with } \\
\text { other measures: }\end{array}$ & Calculation & Source \\
\hline 1 & $\begin{array}{l}\text { OOP Health } \\
\text { Expenditure }\end{array}$ & $\begin{array}{l}\text { All OOP health expenditure } \\
\text { in last } 12 \text { months }\end{array}$ & $\begin{array}{l}\text { Q10, 11, 15, } \\
16,20,22 \\
\text { (section D) }\end{array}$ & CHE numerator & $\begin{array}{l}\text { Sum of Q10, 11, 15, 16, 20, } \\
22\end{array}$ & [15] \\
\hline 2 & $\begin{array}{l}\text { Total } \\
\text { Consumption } \\
\text { Expenditure }\end{array}$ & $\begin{array}{l}\text { Food and non-food consumption } \\
\text { per household in last } 12 \text { months }\end{array}$ & $\begin{array}{l}\text { Worksheet HH } \\
\text { consumption, } \\
\text { item hhtexp }\end{array}$ & CHE denominator & $\begin{array}{l}\text { No calculation, taken } \\
\text { directly from database }\end{array}$ & \\
\hline 3 & $\begin{array}{l}\text { Non-food } \\
\text { consumption } \\
\text { expenditure }\end{array}$ & $\begin{array}{l}\text { Non-food consumption per } \\
\text { household in last } 12 \text { months }\end{array}$ & $\begin{array}{l}\text { Worksheet HH } \\
\text { consumption, } \\
\text { item nfdtexp }\end{array}$ & CHE denominator & $\begin{array}{l}\text { No calculation, taken } \\
\text { directly from database }\end{array}$ & \\
\hline 4 & Capacity to pay & $\begin{array}{l}\text { Same as non-food } \\
\text { consumption expenditure (\#3) }\end{array}$ & & & & \\
\hline 5 & CHE threshold & $\begin{array}{l}\text { Threshold beyond which an OOP } \\
\text { health expenditure is considered a } \\
\text { CHE }\end{array}$ & $\mathrm{n} / \mathrm{a}$ & & $\begin{array}{l}\text { Arbitrary values taken } \\
\text { from literature }\end{array}$ & {$[31,32,41]$} \\
\hline 6 & CHE Incidence & $\begin{array}{l}\text { Households incurring } \mathrm{CHE} \text {, out of } \\
\text { total households }\end{array}$ & $\mathrm{n} / \mathrm{a}$ & $\begin{array}{l}\text { OOP health expenditure } \\
\text { (numerator), } \\
\text { Consumption } \\
\text { expenditure } \\
\text { (denominator) and } \\
\text { threshold }\end{array}$ & $\begin{array}{l}1 \text { if } \# 1 \text { divided by \#2 or \#3 } \\
\text { is beyond \#5 } \\
0 \text { otherwise }\end{array}$ & {$[6,9,20,29,31,41]$} \\
\hline 7 & CHE Intensity & $\begin{array}{l}\text { Average OOP health expenditure } \\
\text { value beyond CHE threshold } \\
\text { (for households incurring CHE) }\end{array}$ & $\mathrm{n} / \mathrm{a}$ & $\begin{array}{l}\text { OOP health expenditure } \\
\text { (numerator), } \\
\text { Consumption } \\
\text { expenditure } \\
\text { (denominator) and } \\
\text { threshold }\end{array}$ & $\begin{array}{l}\text { If } \# 6 \text { is } 1: \# 1 \text { divided by } \# 2 \\
\text { or \#3 minus \#5 } \\
0 \text { otherwise }\end{array}$ & \\
\hline 8 & Impoverishment & $\begin{array}{l}\text { Households incurring CHE } \\
\text { which were pushed below } \\
\text { poverty line by CHE }\end{array}$ & $\mathrm{n} / \mathrm{a}$ & $\mathrm{CHE}$ & $\begin{array}{l}1 \text { if total expenditure minus } \\
\text { OOP health expenditure is } \\
\text { inferior to household's } \\
\text { poverty line, } 0 \text { otherwise }\end{array}$ & {$[7,20,31]$} \\
\hline 9 & Poverty line & $\begin{array}{l}\text { Consumption expenditure per } \\
\text { household assumed to be a } \\
\text { minimum living standard } \\
\text { (food/non-food) }\end{array}$ & $\mathrm{n} / \mathrm{a}$ & Impoverishment & $\begin{array}{l}\text { Sum of adult equivalents in } \\
\text { household, times poverty } \\
\text { line per adult equivalent } \\
(L \$ 65438)\end{array}$ & {$[15]$} \\
\hline
\end{tabular}

intensity for the population was then estimated as the mean overshoot (see Appendix 2 for full details of the methods).

\section{Equity and $\mathrm{CHE}$}

A concentration index $(\mathrm{CI})$ was used to measure the level of equity in the sampled population. A CI is a standard "measure that quantifies the degree of socioeconomic-related inequality in a health variable" [20] and has been often used to quantify $\mathrm{CHE}$ inequality $[3,7,9]$. The concentration index for $\mathrm{CHE}$ incidence $C_{H C}$ is equal to zero when $\mathrm{CHE}$ incidence is distributed perfectly equally (with regards to income), negative if $\mathrm{CHE}$ is concentrated among poor households and positive if $\mathrm{CHE}$ is concentrated among rich households. A weighted concentration index WHC was then calculated to take account of the distribution of $\mathrm{CHE}$ incidence across different socio-economic quintiles. If the concentration index $C_{H C}$ is negative, then the rank-weighted
CHE incidence $\overline{W H C}$ would be greater than the unweighted $\mathrm{CHE}$ incidence $\overline{H C}$, reflecting the fact that poorer people are more affected by $\mathrm{CHE}$ than richer people (see Appendix 3).

\section{OOP health expenditure impoverishment effect}

A limitation of comparing total consumption expenditure to poverty lines is that total consumption expenditure includes expenditures, such as health expenditures, that prevent welfare deterioration rather than increase welfare [16]. For this reason, the impoverishment effect was used to measure how many households were pushed below the poverty line by OOP health expenditures, whether they are catastrophic or not. To measure how many households were pushed below the poverty line by OOP health expenditure, the incidence of poverty before OOP health expenditures was compared with the incidence of poverty after OOP health expenditures $[20,30$, 
31]. The poverty line was defined as $65,438 \mathrm{~L} \$$ - the Liberian poverty line per each adult equivalence, as per the HIES 2014 methodological appendix [15]. The impoverishing effect of OOP health expenditure is the difference between poverty incidence before OOP health expenditure and poverty incidence after OOP health expenditure (see Appendix 4 for the full methods).

\section{Households forgoing healthcare}

Only households who have purchased healthcare services can incur CHE: when the required healthcare services are unaffordable or inaccessible for any reason, a household forgoes healthcare services needed, does not spend any money on healthcare services, and bears the lower quality of life due to the untreated health shock. Such untreated health shock may lead to household impoverishment through loss of productivity and/or income.

Given the above limitation of CHE, HFH incidence has been frequently assessed by including questions on HFH in a survey [17], (e.g. Commonwealth Fund International Health Policy Survey [24], population-based and country specific surveys $[4,10])$. This HFH measurement methodology is subjective and is therefore difficult to use in cross-country comparisons. Finally, this method is dependent on having an HFH question in the survey: while limited, there is a cost related to adding a question to a survey.

A needs-based approach such as proposed by Pradhan and Prescott [21] could address this issue of subjectivity [21]. However, their approach appears to be complex and has not been widely applied. This paper develops a simplified needs-based approach to measure HFH incidence. Its limitations are that.

To identify those households that forgo healthcare services, their OOP needs to be below the expected value of the healthcare services that they need. The incidence of households forgoing healthcare services (HFH) could then be represented by the percentage of households that experienced a health shock, have not incurred CHE and have not spent more than a specific threshold value, in $O O P$ health expenditure. The threshold value can be chosen to reflect the minimum OOP health expenditure needed to cope with a health shock, for example, the value of a basic healthcare intervention in the country e.g. a blood test. It is important that households forgoing healthcare have not incurred CHE so that the two measures are mutually exclusive and can be summed to estimate the percentage of households who are not financially protected.

The Liberia HIES 2014 reports if a household has had a health shock, where a health shock is defined as the occurrence of at least one event among severe illness, chronic illness, accident or death of a household member [14] within the last 12 months. For the case of
Liberia, US\$10 threshold was chosen as the minimum value of care needed to cope with a health shock, although such care is likely to cost more than US\$10 (as mentioned, a basic blood test, possibly not available in public clinics, may cost US $\$ 10$ in a private clinic, even without considering transport costs to access state funded healthcare services). Therefore, a household was defined as forgoing healthcare if they fulfilled three criteria: reported a health shock, had a health expenditure of less than US\$10 and did not incur CHE (Appendix 5 describes the full methodology).

A sensitivity analysis was then carried out to check how the index varies in relation to the threshold cost of healthcare used (US\$10) (thresholds ranging from 0 US\$ to 10,000 US\$), following the same principles as the sensitivity analysis applied to the CHE estimation.

Sampling weights have been used throughout the analysis to improve sample representativeness [25]. Data were analysed using Microsoft Excel (Microsoft, Washington, USA) and Stata/IC 14 (StataCorp, Texas, USA) for Windows.

\section{Results \\ Descriptive statistics}

The characteristics of the sample are presented in Table 2. Most households (60\%) lived in urban areas, while the remaining households (40\%) lived in rural areas. Households with less than 5 members were $58 \%$ of the total, and while in most households (55\%) there was a child below 5 years old, there was an adult above 60 years old in only $14 \%$ of the households. Almost half $(43 \%)$ of the heads of household in the sample have no formal education. Most heads of household are male (71\%), aged below 44 years old (63\%). Approximately one fifth (19\%) of all households suffered a health shock in the last 12 months.

Relevant expenditure measures are shown in Table 3. The mean annual total household expenditure and OOP health expenditure were $\mathrm{L} \$ 217,800$ and $\mathrm{L} \$ 2800$ respectively (exchange rate: US\$ $1=92 \mathrm{~L} \$$, source: oanda.com, average exchange rate at December 2014). The OOP health expenditure was higher for wealthier households than for the poor, and for urban households than for the rural, although the prevalence of health shocks was quite similar across different wealth quintiles and across rural/ urban residential areas. Almost a fifth (17\%) of the households in the poorest quintile have no (zero) OOP health expenditure, suggesting that they may have forgone healthcare services due to limited access or affordability.

\section{CHE incidence, intensity, equity}

CHE incidence and intensity are shown in Table 4. CHE was experienced by between $0.4 \%$ (95\% CI: $0.2-0.6 \%$ ) 
Table 2 Descriptive statistics: sample characteristics

\begin{tabular}{|c|c|c|}
\hline & $\%$ of households & Number of Households in sample (n) \\
\hline \multicolumn{3}{|l|}{ Residence } \\
\hline Rural & $40 \%$ & 2546 \\
\hline Urban & $60 \%$ & 1539 \\
\hline \multicolumn{3}{|l|}{ Household size } \\
\hline 1 & $12 \%$ & 443 \\
\hline 2 & $13 \%$ & 478 \\
\hline 3 & $16 \%$ & 610 \\
\hline 4 & $17 \%$ & 704 \\
\hline $5+$ & $42 \%$ & 1850 \\
\hline \multicolumn{3}{|l|}{ Household age composition } \\
\hline Presence of children $<5$ years & $55 \%$ & 2353 \\
\hline Presence of adults $>60$ years & $14 \%$ & 715 \\
\hline \multicolumn{3}{|l|}{ Age of head of household } \\
\hline$<25$ years old & $9 \%$ & 291 \\
\hline 25-34 years old & $27 \%$ & 1017 \\
\hline 35-44 years old & $27 \%$ & 1138 \\
\hline $45-54$ years old & $20 \%$ & 848 \\
\hline$>54$ years old & $17 \%$ & 791 \\
\hline \multicolumn{3}{|l|}{ Education of head of household } \\
\hline None & $43 \%$ & 1905 \\
\hline Some or completed primary & $12 \%$ & 609 \\
\hline Some or completed secondary & $38 \%$ & 1399 \\
\hline More than secondary & $7 \%$ & 172 \\
\hline \multicolumn{3}{|l|}{ Gender of head of household } \\
\hline Male & $71 \%$ & 3014 \\
\hline Female & $29 \%$ & 1071 \\
\hline \multicolumn{3}{|c|}{ Suffered a health shock (chronic or severe illness, accident, or death) } \\
\hline Yes & $19 \%$ & 765 \\
\hline No & $81 \%$ & 3320 \\
\hline
\end{tabular}

Source: Liberia Household income and expenditure survey, 2014

Table 3 Household expenditure (in thousands of $L \$$ ), reporting of illness and utilization measures

\begin{tabular}{|c|c|c|c|c|c|}
\hline & Total Expenditure & Non-food Expenditure & $\begin{array}{l}\text { OOP } \\
\text { Health } \\
\text { Expenditure }\end{array}$ & $\begin{array}{l}\text { Prevalence } \\
\text { of health } \\
\text { shocks }\end{array}$ & Utilization, inpatient \\
\hline Full Sample & 217.8 & 87.4 & 2.8 & $19 \%$ & $20 \%$ \\
\hline \multicolumn{6}{|l|}{ Quintile } \\
\hline Poorest (1) & 107.8 & 26.6 & 1.9 & $16 \%$ & $23 \%$ \\
\hline 2 & 168.6 & 46.7 & 1.9 & $20 \%$ & $24 \%$ \\
\hline 3 & 229.9 & 78.4 & 3.1 & $21 \%$ & $21 \%$ \\
\hline 4 & 310.5 & 119.0 & 3.0 & $19 \%$ & $21 \%$ \\
\hline Wealthiest (5) & 574.4 & 287.3 & 3.5 & $17 \%$ & $16 \%$ \\
\hline \multicolumn{6}{|l|}{ Residence area } \\
\hline Urban & 248.3 & 111.7 & 3.2 & $19 \%$ & $22 \%$ \\
\hline Rural & 171.2 & 50.2 & 2.1 & $18 \%$ & $18 \%$ \\
\hline
\end{tabular}

Source: Liberia Household income and expenditure survey, 2014. Average exchange rate from Oanda.com, December 2014 
Table 4 CHE Incidence and Intensity, by different thresholds

\begin{tabular}{|c|c|c|c|c|}
\hline \multirow[t]{2}{*}{ Threshold } & \multicolumn{2}{|c|}{ As a share of total expenditure } & \multicolumn{2}{|c|}{ As a share of capacity to pay (non-food expenditure) } \\
\hline & $10 \%$ & $25 \%$ & $30 \%$ & $40 \%$ \\
\hline $\begin{array}{l}\text { CHE Incidence }(95 \% \mathrm{Cl}) \\
{[\mathrm{HH} \text { count }]}\end{array}$ & $1.7 \%(1.3-2.2 \%)[70]$ & $0.4 \%(0.2-0.6 \%)[19]$ & $2.1 \%(1.7-2.5 \%)[102]$ & $1.4 \%(1.0-1.7 \%)[69]$ \\
\hline CHE Intensity $(95 \% \mathrm{Cl})$ & $14.4 \%(7.4-21.4 \%)$ & $34.0 \%(14.5-53.6 \%)$ & $37.4 \%(22.7-52.0 \%)$ & $44.6 \%(24.2-65.0 \%)$ \\
\hline Concentration Index & -0.03 & $-0.44^{b}$ & $-0.24^{c}$ & $-0.33^{c}$ \\
\hline Weighted CHE Incidence & $1.8 \%$ & $0.5 \%$ & $2.6 \%$ & $1.8 \%$ \\
\hline
\end{tabular}

${ }^{a}=$ significant at the 0.05 level, ${ }^{b}=$ significant at the 0.01 level, ${ }^{c}=$ significant at the 0.001 level

and $2.1 \%$ (95\% CI: $1.7-2.5 \%)$ of the households in Liberia, depending on the threshold used. The intensity of $\mathrm{CHE}$ ranged from $14.4 \%$ (95\% CI: 7.4-21.4\%) to 44.6\% (95\% CI: 24.2-65.0\%), depending on the threshold used. In other words, households incurring $\mathrm{CHE}$ have incurred, on average, expenditures of $14.4 \%$ (95\% CI: 7.4-21.4\%) of total household expenditure over and above their average household expenditure.

The concentration indices were negative across all thresholds considered, and only the concentration index calculated at the $10 \%$ threshold of total expenditure was not significant against the null hypothesis that $\mathrm{CHE}$ is equal across quintiles. As expected, the weighted $\mathrm{CHE}$ incidence, resulting from applying the concentration index weighting to the $\mathrm{CHE}$ incidence, was higher than the crude/unweighted $\mathrm{CHE}$ incidence; implying that $\mathrm{CHE}$ was concentrated among poorer households.

$\mathrm{CHE}$ incidence sensitivity analyses are presented in Fig. 2 and show that CHE incidence was higher when using a non-food expenditure threshold.

\section{Impoverishment effect of OOP health expenditure}

The percentage of households living below poverty line in Liberia before and after considering OOP health expenditures is presented in Table 5 . The table shows that $53.6 \%$ of sampled households were already living below the overall poverty line $(44.1 \%$ below the food poverty line) before considering OOP health expenditures. After considering OOP health expenditures, the incidence of sampled households living below the overall poverty line increases by $0.6 \%$ (an increase of $1.6 \%$ using the food poverty line).

\section{HFH incidence}

The measure of $\mathrm{HFH}$ incidence suggests that many households (HFH incidence: 8.0, 95\% CI: 7.2-8.9\%) have forgone healthcare services needed due to a health shock (i.e., not incurred CHE, experienced a health shock and spent less than US\$10 in healthcare costs) and therefore are not financially protected. HFH incidence sensitivity analysis (Fig. 3) shows that even more households (towards a maximum of $\sim 18 \%$ of total households) have experienced a health shock and have not incurred $\mathrm{CHE}$ as the threshold value increases.

\section{Discussion}

This study has measured catastrophic health expenditures in Liberia, how this varies by income group and the extent to which these measures represent financial risk protection in a low-income country. OOPs represent $20 \%$ of health expenditures in Liberia [36] and so provide a good indicator of financial health risk

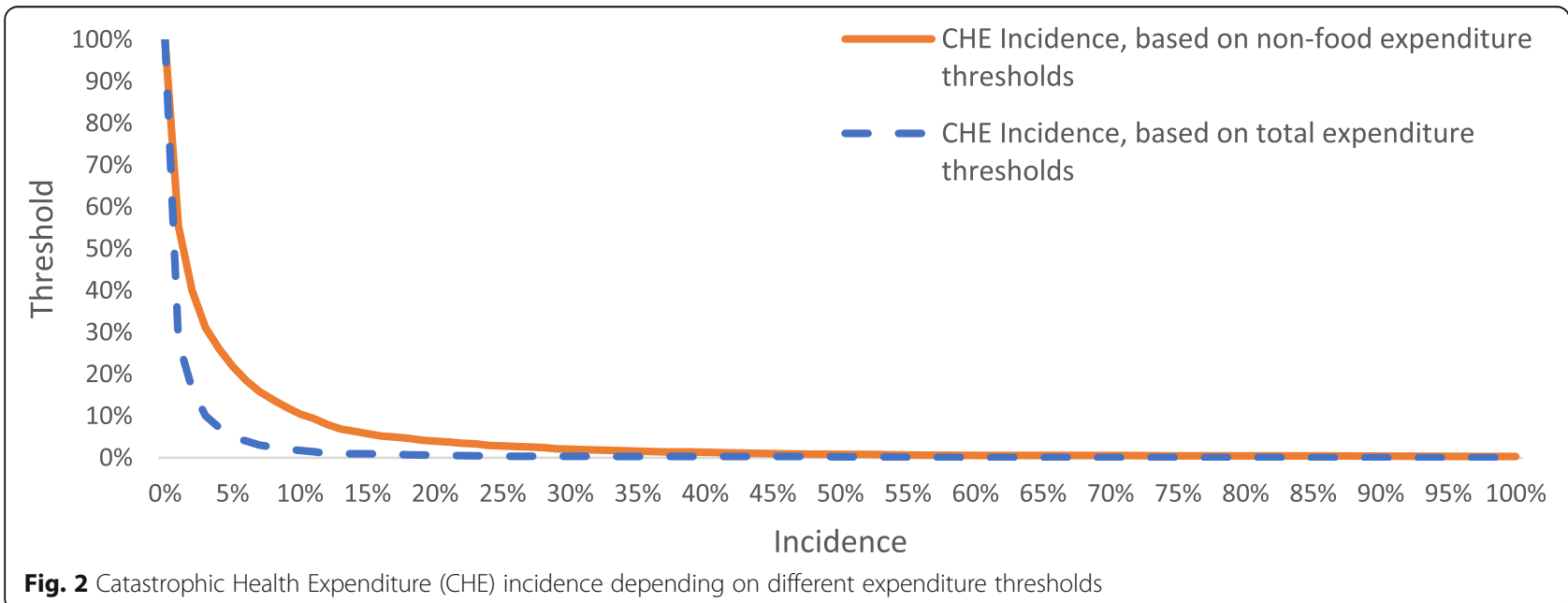


Table 5 Impoverishing effects of OOP health expenditure

\begin{tabular}{|c|c|c|c|c|}
\hline \multirow[t]{2}{*}{ Poverty Line } & \multicolumn{2}{|l|}{$\%$ sample households below poverty line } & \multirow{2}{*}{$\begin{array}{l}\text { Absolute } \\
\text { change } \\
{[(2)-(1)]}\end{array}$} & \multirow{2}{*}{$\begin{array}{l}\text { Relative } \\
\text { change } \\
{[((2) /} \\
(1))-1]\end{array}$} \\
\hline & Gross of OOP Health Expenditure (1) & Net of OOP Health Expenditure (2) & & \\
\hline Overall poverty line & $53.6 \%$ & $54.2 \%$ & $0.6 \%$ & $1.1 \%$ \\
\hline Food poverty line & $44.1 \%$ & $45.7 \%$ & $1.6 \%$ & $3.6 \%$ \\
\hline
\end{tabular}

protection in a health system where many healthcare services cannot be provided by the public health system free at point of care. The study shows that OOP health expenditures are a significant source of financial risk for Liberian households, especially for poorer households (concentration index: -0.03 to -0.44 ). Depending on the threshold used, $0.4 \%$ (95\% CI: $0.2-0.6 \%, 25 \%$ total expenditure threshold) to $2.1 \%$ (95\% CI: $1.7-2.5 \%, 30 \%$ non-food expenditure threshold) of Liberian households incur CHE every year, and 1.6\% of Liberian households fall into poverty every year due to OOP health expenditure. These findings are consistent with findings from other developing countries e.g. Malawi, Ghana, Swaziland and Mongolia [3, 8, 16, 18]. The findings also show that CHE intensity in Liberia is generally greater than in other countries $[3,6,18]$, and it ranges from 14.4\% (95\% CI: 7.4-21.4\%, 10\% total expenditure threshold) to $44.6 \%$ (95\% CI: $24.2-65.0 \%, 40 \%$ total expenditure threshold) depending on the threshold chosen.

The higher intensity of CHE in Liberia is possibly due to widespread poverty and the more frequent occurrence of $\mathrm{CHE}$ in lower socioeconomic quintiles. The difference in CHE between urban and rural is also important to note. Since the prevalence of health shocks is similar in rural and urban areas, OOP health expenditure and utilization of inpatient services should be similar across urban and rural areas but this is not the case. There are lower OOP health expenditures and healthcare utilization rates in rural areas. This suggests that healthcare services in rural areas are inaccessible due to either supply issues (i.e., there are few or no healthcare providers) and/or demand issues (i.e., rural households are poorer and cannot afford to buy healthcare).

The analysis demonstrates that while CHE incidence can "look" low at higher thresholds, it is in fact very high when the threshold is low. To understand this variation better, the CHE incidence curve allowed a comparison of CHE incidence based on total expenditure and nonfood expenditure. The higher $\mathrm{CHE}$ incidence resulting from using non-food expenditure thresholds suggests that Liberians are not substituting food for healthcare, probably because food consumption is already low

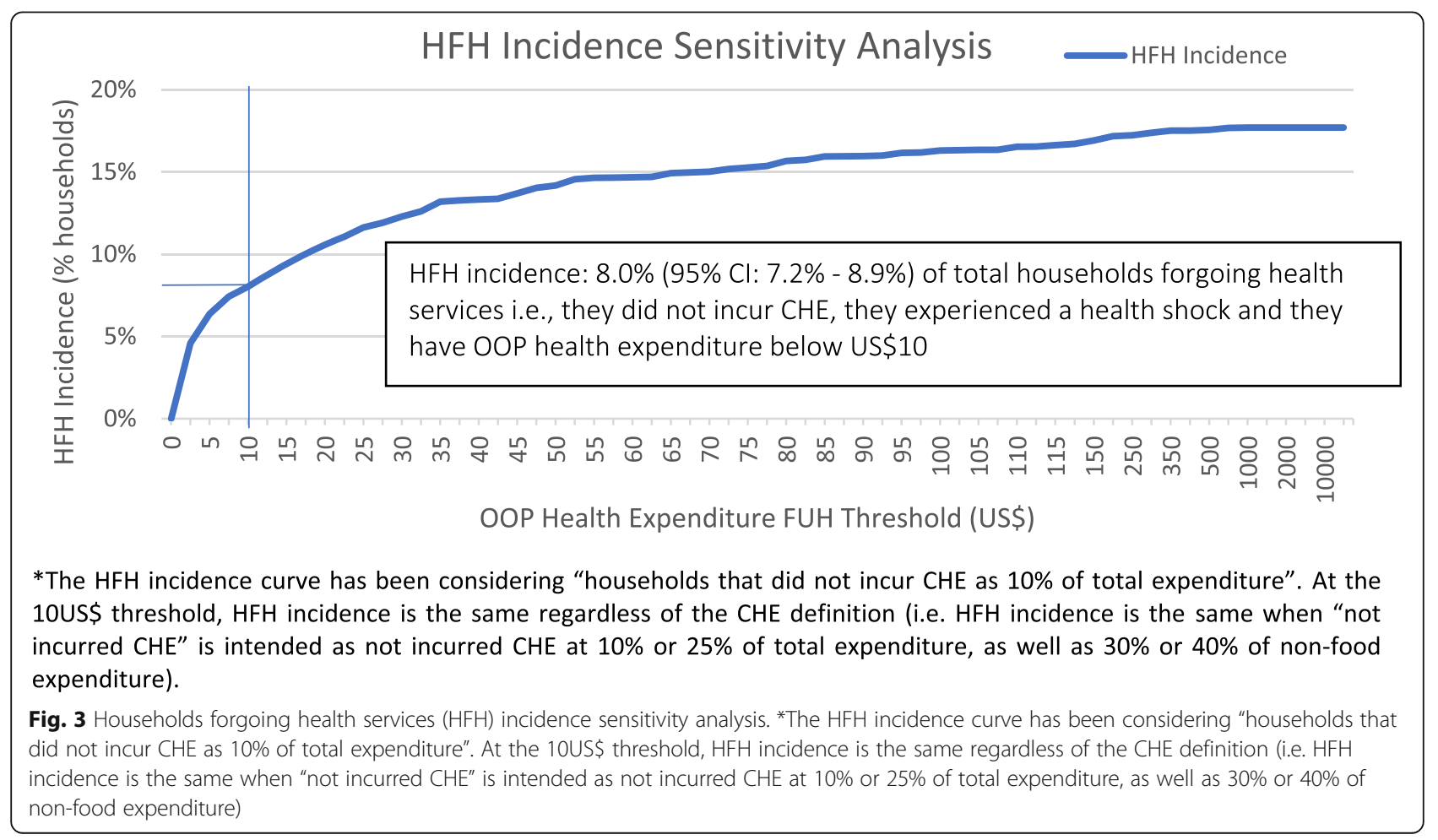


(percentage of households below the food poverty line: $\sim 45 \%$ [15]). However, neither of these analyses can take account of the decision not to incur health expenditures because of financial risk or sub-optimal supply of healthcare services as suggested by the rural-urban differences in CHE. The study proposed a simple method to explore the extent to which this happens in the form of incidence of healthcare forgone (HFH) (experiencing a health shock, having OOP health expenditure that is too low to cover most health conditions $(<$ US\$10) while not experiencing $\mathrm{CHE}$ ).

HFH incidence was over 5 times the incidence of impoverishing expenditure and 3 times the incidence of CHE (at the higher threshold). Given the high rates of poverty in Liberia, the implication is that these households could not afford or access the healthcare services that they need. It raises the question whether $\mathrm{CHE}$ is a sufficient measure of financial risk protection where high levels of poverty lead to low uptake of services and whether improved financial risk protection understanding may impact decision making; for example, policy makers may consider actions that address HFH. It is important to remember that those households that forgo healthcare may not spend money on healthcare but the impact of untreated illness may then lead to impoverishment in other ways such as reduction in productivity and/or income.

The study suffers from some limitations, most notably the small sample size of individuals experiencing CHE. For a threshold equal to $25 \%$ of total expenditure, the sample i.e., households incurring CHE, is small (19 households). The study addresses this by varying the threshold and the use of the CHE incidence curves which indicate that the incidence rates are still relatively high at the lower threshold level. However, for the measure of intensity the small sample size leads to parameter uncertainty (i.e., low number of households incurring CHE), and for this reason, the confidence intervals for the intensity measure are very large. Other survey related limitations include the 30day recall period for some of the health expenditures being considered in OOP health expenditures and the fact that other non-financial costs (e.g. time spent to receive healthcare services) have not been considered due to data availability limitations. Since income is annual, annualization was required. It is impossible to know with certainty to what extent such "past 30 days" expenses have been repeated during the full year. However, the impact of this is unknown and could result in an under- or overestimation of CHE. In addition, this study only included cross-sectional data from HIES 2014. The HIES 2016 data, which is now available [13], would capture the impact of the Ebola virus as well as facilitate sub-group analysis. However, these limitations do not impact the demonstration of the effectiveness of $\mathrm{HFH}$ incidence to assess financial risk protection and the analysis of the 2014 survey can be taken as a baseline and indicate areas of further research when assessing financial health risk protection between 2014 and 2016 .

The $\mathrm{HFH}$ incidence measure is a proposition. HFH could be measured via adding questions to surveys (e.g. living standards surveys) or by using more elaborate needs-based approaches, as proposed in the literature [17, 21]. It should also be noted that this measure does not explore why people may not get the healthcare they need, and that the reasons for forgoing healthcare may not be financial (e.g. voluntary refusal to get modern healthcare, not knowing that a treatment exist, impossibility to access treatment or information due to non-financial reasons). It is also important to note that some households may have accessed healthcare without a financial expenditure (e.g. where services have been provided free of charge as a goodwill gesture or via a health program, or where services were paid directly by another household). While a sensitivity analysis was provided, it was not possible to assess this formally. Consequently, the results may represent an over-estimate of actual HFH.

\section{Conclusion}

Financial catastrophe due to OOP health expenditure is a significant problem in Liberia and adversely affects the poorer socio-economic quintiles. Whereas catastrophic health expenditure incidence provides a good measure of the degree to which a population is affected by OOP, incidence curves provide a useful way to compare the impact of different thresholds and different measures of CHE. However, financial risk protection measures are incomplete as they fail to include those households not accessing healthcare due to financial constraints. A simple measure of incidence of households forgoing healthcare shows this is a significant problem in Liberia. The high level of CHE, impoverishing expenditure and $\mathrm{HFH}$ support the implementation of health system reforms that are equitable and increase financial risk protection in Liberia, protecting Liberians, especially the poorest, from financial catastrophe and from forgoing healthcare. These findings can also be used as a baseline against which future evaluations of CHE and equity of health policies can be measured. Although more research is needed to better understand the consequences of forgoing healthcare and improve the methodology for measuring its incidence, the measure of $\mathrm{HFH}$ incidence proposed in this paper provides a simple and flexible method to demonstrate its importance.

\section{Appendix 1}

Catastrophic health expenditure incidence methods

If we let $T$ be OOP health expenditure and $x$ be the household resources of a given household, $i$, then 
headcount of $\mathrm{CHE}$ in the form of the dummy variable $H C$ is calculated as follows:

$$
H C_{j}=1 \text { if }\left(\frac{T_{i}}{x_{i}}\right)-z_{j}>0,0 \text { otherwise }
$$

where, $z$ is the threshold that can assume only two $j$ values: $10 \%$ or $25 \%$ of $x_{i}$ when $x$ is total expenditure; and, 30 and $40 \%$ when $x$ is capacity to pay. CHE incidence is then calculated as:

$$
\overline{H C}_{j}=\frac{1}{N} \sum_{i=1}^{N} H C_{i j}
$$

\section{Appendix 2}

\section{Catastrophic health expenditure intensity methods}

$T$ be OOP health expenditure and $x$ be the household resources of a given household, $i$, then intensity of $\mathrm{CHE}$ takes the form of a quantitative variable $O$ and is calculated as follows:

$$
O_{i x}=\left(\frac{T_{i}}{x_{i}}\right)-z_{j}
$$

where, $z$ is the threshold that can assume only two $j$ values: $10 \%$ or $25 \%$ of $x_{i}$ when $x$ is total expenditure; and, 30 and $40 \%$ when $x$ is capacity to pay.

The average intensity for the population experiencing $\mathrm{CHE}$ (i.e., positive mean overshoot), $\bar{O}$, is as follows:

$$
\bar{O}_{j x}=\frac{\sum_{i=1}^{N} O_{i j x}}{\sum_{i=1}^{N} H C_{i j x}}
$$

\section{Appendix 3}

\section{Equity and CHE methods: concentration index}

A "rank-weighted CHE incidence" was estimated to take account of the distribution of CHE incidence across different socio-economic quintiles. In mathematical terms, the rank-weighted CHE incidence $\overline{W H C}$ was calculated using concentration index $C_{H C}$ and $\mathrm{CHE}$ incidence $\overline{H C}$ as follows:

$$
\overline{W H C}=\overline{H C} *\left(1-C_{H C}\right)
$$

Where, the concentration index headcount is

$$
C_{H C}=\frac{2}{\mu_{H C}} \operatorname{cov}(H C, \operatorname{rank})
$$

And $\left(-1<C_{H C}<+1\right)$.

The concentration index provides a distribution of the socioeconomic status across the sampled households [2,
6, 8]. The index $C_{H C}$ was calculated using the conindex Stata command [40] through which households were allocated weights according to their rank in the socioeconomic distribution. The concentration index distribution gives a weight of 2 (the poorest households) and 0 (the richest) $[18,29]$ : the result is that $C_{H C}$ is equal to zero when $\mathrm{CHE}$ incidence is distributed perfectly equally (with regards to income), negative if CHE is concentrated among poor households and positive if CHE is concentrated among rich households. Normalised indices [39] for binary variables have been calculated too to check for any difference versus the standard concentration index. Since HIES 2014 sampling methods are probabilistic, sampling weights have been applied using the pweight option.

\section{Appendix 4}

\section{Impoverishing effect methods}

Household poverty line for each household has been measured in the following way: if household i has $n$ individual household members $\mathrm{j}$, and each individual household member has an adult equivalence score $A E_{j}$, then each household i poverty line $H H P L_{i}$ is defined as:

$$
H H P L_{i}=\left(\sum_{j=1}^{n} A E_{j} * \text { Individual }_{j}\right) * 65438 L
$$

where $65,438 \mathrm{~L} \$$ is the Liberian poverty line per each adult equivalence, as per the HIES 2014 methodological appendix [14].

A dummy variable $p-p r e_{i}$ takes the value 1 when household $i$ total consumption expenditure $x_{i}$ is below its poverty line $H H P L_{i}$, and 0 , otherwise, then the incidence of poverty prior to OOP is:

$$
\overline{p-p r e}=\frac{1}{N} \sum_{i=1}^{N} p-\text { pre }_{i}
$$

where $p-$ pre $_{i}=1$ if $x_{i}<H H P L_{i}$, 0 otherwise

It is implied in this $p-p r e_{i}$ formula that OOP health expenditure do NOT affect the household income as it is compared to the poverty line.

A dummy variable $p$ - post $_{i}$ takes the value 1 when household $i$ total consumption expenditure $x_{i}$ minus OOP health expenditure $T_{i}$ is below the poverty line $H H P L_{i}$, and 0 , otherwise:

$$
\overline{p-p o s t}=\frac{1}{N} \sum_{i=1}^{N} p-\text { post }_{i}
$$

where $p-$ post $_{i}=1$ if $\left(x_{i}-T_{i}\right)<H H P L_{i}, 0$ otherwise [7, 17, 29].

In this $p$ - post $t_{i}$ formula, the total consumption expenditure $X_{i}$ of household $\mathrm{i}$ is discounted by the OOP health expenditure $T_{i}$. The impoverishing effect of OOP health 
expenditure is the difference between poverty incidence before OOP health expenditure $(\overline{p-p r e})$ and poverty incidence after OOP health expenditure $(\overline{p-p o s t})$.

\section{Appendix 5}

Households forgoing healthcare methods

Let $\mathrm{HC}$ be the binary variable representing whether household i incurred CHE, Health Shock a binary variable representing whether household i reported a health shock or not, and $T$ be household i OOP health expenditure, then $\mathrm{HFH}$ is a binary variable defined as:

$$
\begin{aligned}
H F H_{i j} & =1 \text { if } H C=0, \text { Health Shock }=1 \text { and } T_{i} \\
& <U S 10 ; 0 \text { otherwise }
\end{aligned}
$$

The incidence of HFH at the population level is estimated as:

$$
\overline{H F H}_{j x}=\frac{1}{N} \sum_{i=1}^{N} H F H_{i j x}
$$

using total expenditure $\mathrm{x}$ as $\mathrm{CHE} \mathrm{HC}$ denominator, and different CHE thresholds $j$.

\section{Acknowledgments}

The authors would like to thank London School of Hygiene and Tropical Medicine MSc project team for the guidance and comments in the early stages of this research.

\section{Authors' contributions}

$J G$ analysed and interpreted the household data regarding Liberian households, including health expenditures, total general expenditures, etc. JG wrote the initial draft of the manuscript. LG interpreted the results and provided major inputs to the writing, including writing some parts of the article, and the planning of the article. All authors read and approved the final manuscript.

\section{Funding}

No funding was secured for this study.

\section{Availability of data and materials}

The datasets used is available publicly on World Bank Microdata portal at http://microdata.worldbank.org/index.php/catalog/2563. The dataset including analyses is available from the corresponding author on reasonable request.

\section{Ethics approval and consent to participate}

This article has been prepared using secondary data (Household Income and Expenditure Survey of Liberia, 2014) from Liberia Institute of Statistics and Geo-Information Services, available at http://microdata.worldbank.org/index. php/catalog/2563 to anyone registering on World Bank Microdata portal with an email. A more comprehensive version of this study was submitted as a partial fulfilment of the requirements for the degree of MSc in Public Health at London School of Hygiene and Tropical Medicine (LSHTM) in September 2018: for this reason, it has been approved by the LSHTM Ethics committee in January 2018. Thus, no ethical approval is required separately for this study.

\section{Consent for publication}

Not applicable.

\section{Competing interests}

The authors declare that they have no competing interests.
Received: 2 July 2019 Accepted: 18 November 2019

Published online: 10 December 2019

\section{References}

1. Abiiro GA, De Allegri M. Universal health coverage from multiple perspectives: a synthesis of conceptual literature and global debates. BMC Int Health Hum Rights. 2015;15(1):1-7. https://doi.org/10.1186/s12914-0150056-9 BMC International Health and Human Rights.

2. Adam Wagstaff, (2005) The bounds of the concentration index when the variable of interest is binary, with an application to immunization inequality. Health Economics 14 (4):429-432.

3. Akazili J, et al. Assessing the catastrophic effects of out-of-pocket healthcare payments prior to the uptake of a nationwide health insurance scheme in Ghana. Glob Health Action. 2017;10(1):1289735. https://doi.org/10.1080/ 16549716.2017.1289735 Informa \{UK\} Limited.

4. Baggio $\mathrm{S}$, et al. Addictive behaviors and healthcare renunciation for economic reasons in a French population-based sample. Int J Drug Policy. 2017. https://doi.org/10.1016/j.drugpo.2017.07.004

5. Boerma T, et al. Monitoring progress towards universal health coverage at country and global levels. PLoS Med. 2014;11(9). https://doi.org/10.1371/ journal.pmed.1001731

6. Buigut S, Ettarh R, Amendah DD. Catastrophic health expenditure and its determinants in Kenya slum communities. Int J Equity Health. 2015;14(1) https://doi.org/10.1186/s12939-015-0168-9 Springer Nature.

7. Chuma J, Maina T. Catastrophic health care spending and impoverishment in Kenya. BMC Health Serv Res. 2012;12(1). https://doi.org/10.1186/14726963-12-413 Springer Nature.

8. Dorjdagva J, et al. Catastrophic health expenditure and impoverishment in Mongolia. Int J Equity Health. 2016;15(1). https://doi.org/10.1186/s12939016-0395-8 Springer Nature.

9. Ghimire M, Ayer R, Kondo M. Cumulative incidence, distribution, and determinants of catastrophic health expenditure in Nepal: results from the living standards survey. Int J Equity Health. 2018;17(1). https://doi.org/10. 1186/s12939-018-0736-x Springer Nature.

10. Guessous I, et al. High prevalence of forgoing healthcare for economic reasons in Switzerland: a population-based study in a region with universal health insurance coverage. Prev Med. 2012;55(5):521-7. https://doi.org/10. 1016/j.ypmed.2012.08.005.

11. Hsu J, et al. Measuring financial protection against catastrophic health expenditures: methodological challenges for global monitoring. Int J Equity Health. 2018;17(1). https://doi.org/10.1186/s12939-018-0749-5 Springer Nature.

12. Kentoffio K, et al. Charting health system reconstruction in post-war Liberia: a comparison of rural vs. remote healthcare utilization. BMC Health Serv Res. 2016;16(1):1-9. https://doi.org/10.1186/s12913-016-1709-7 BMC Health Services Research.

13. Liberia Institute for Statistics and Geo-Information Services (LISGIS) (2018) Liberia - household income and expenditure survey 2016. Available at: http://microdata.worldbank.org/index.php/catalog/2986. Accessed 10 Feb 2019.

14. Liberia Institute of Statistics and Geo-Information Services (LISGIS) (2014) Household income and expenditure survey 2014 - questionnaire.

15. Liberia Institute of Statistics and Geo-Information Services (LISGIS) (2016) Household income and expenditure survey 2014 - statistical abstract. Available at: https://www.lisgis.net/pg_img/ LiberiaStatisticalAbstractFINAL.pdf.

16. Mchenga M, Chirwa GC, Chiwaula LS. Impoverishing effects of catastrophic health expenditures in Malawi. Int J Equity Health. 2017;16(1). https://doi. org/10.1186/s12939-017-0515-0 Springer Nature.

17. Moreno-Serra R, Millett C, Smith PC. Towards improved measurement of financial protection in health. PLoS Med. 2011;8(9):8-13. https://doi.org/10. 1371/journal.pmed.1001087.

18. Ngcamphalala C, Ataguba JE. An assessment of financial catastrophe and impoverishment from out-of-pocket health care payments in Swaziland. Glob Health Action. 2018;11(1):1428473. https://doi.org/10.1080/16549716. 2018.1428473 Informa $\{$ UK\} Limited.

19. Owen O'Donnell, Stephen O'Neill, Tom Van Ourti, Brendan Walsh, (2018) Conindex: Estimation of Concentration Indices. The Stata Journal: Promoting communications on statistics and Stata 16 (1):112-138.

20. O'Donnell $\mathrm{O}$, et al. Analyzing health equity using household survey data: The World Bank; 2007. https://doi.org/10.1596/978-0-8213-6933-3. 
21. Pradhan $M$, Prescott N. Social risk management options for medical care in Indonesia. Health Econ. 2002;11(5):431-46. https://doi.org/10.1002/hec.689.

22. Ruger JP. Catastrophic health expenditure. Lancet. 2003. https://doi.org/10. 1016/s0140-6736(03)14376-0.

23. Saksena P, Hsu J, Evans DB. Financial risk protection and universal health coverage: evidence and measurement challenges. PLoS Med. 2014;11(9): e1001701. https://doi.org/10.1371/journal.pmed.1001701 Public Library of Science (\{PLOS\}).

24. Schoen C, Osborn R. The commonwealth fund 2010 international health policy survey in eleven countries. London: Commonwealth Fund; 2010.

25. Solon G, Haider SJ, Wooldridge JM. What are we weighting for? J Hum Resour. 2015. https://doi.org/10.3368/jhr.50.2.301.

26. Sudhinaraset $M$, et al. What is the role of informal healthcare providers in developing countries? A systematic review. PLoS One. 2013;8(2):e54978. https://doi.org/10.1371/journal.pone.0054978 Public Library of Science.

27. Sweeney $\mathrm{S}$, et al. Measuring income for catastrophic cost estimates: limitations and policy implications of current approaches. Soc Sci Med. 2018;215(November 2017):7-15. https://doi.org/10.1016/j. socscimed.2018.08.041

28. United Nations (2016) Goal 3: sustainable development knowledge platform. Available at: https://sustainabledevelopment.un.org/sdg3. Accessed 10 Feb 2019.

29. Wagstaff A, Flores G, Hsu J, et al. Progress on catastrophic health spending in 133 countries: a retrospective observational study. Lancet Glob Health. 2018a;6(2):e169-79. https://doi.org/10.1016/s2214109x(17)30429-1 Elsevier \{BV\}.

30. Wagstaff A, Flores G, Smitz MF, et al. Progress on impoverishing health spending in 122 countries: a retrospective observational study. Lancet Glob Health. 2018b;6(2):e180-92. https://doi.org/10.1016/S2214-109X(17)30486-2.

31. Wagstaff $A$, van Doorslaer E. Catastrophe and impoverishment in paying for health care: with applications to Vietnam 1993-1998. Health Econ. 2003; 12(11):921-33. https://doi.org/10.1002/hec.776 Wiley.

32. World Bank; World Health Organization (2017) Tracking universal health coverage: 2017 global monitoring report. doi: ISBN 978-92-4-151355-5.

33. World Bank (2015a) GDP per capita, PPP (current international \$) | Data. Available at: https://data.worldbank.org/indicator/NY.GDP.PCAP.PP.CD. Accessed 16 Oct 2019

34. World Bank (2015b) Maternal mortality ratio (modeled estimate, per 100,000 live births) | Data. Available at: https://data.worldbank.org/indicator/SH.STA. MMRT. Accessed 16 Oct 2019

35. World Bank (2015c) Mortality rate, under-5 (per 1,000 live births) | Data. Available at: https://data.worldbank.org/indicator/SH.DYN.MORT. Accessed 16 Oct 2019

36. World Bank (2015d) Out-of-pocket expenditure (\% of current health expenditure) | Data. Available at: https://data.worldbank.org/indicator/SH. XPD.OOPC.CH.ZS. Accessed 14 Feb 2019.

37. World Bank (2017) Liberia | Data. Available at: https://data.worldbank.org/ country/liberia. Accessed 10 Feb 2019.

38. World Bank (2018) World Bank Country and Lending Groups. Available at: https://datahelpdesk.worldbank.org/knowledgebase/articles/906519-worldbank-country-and-lending-groups. Accessed 7 Jan 2019.

39. World Health Organization (2015) Global Health Observatory. Available at: http://apps.who.int/gho/data/node.main.GHEDOOPSCHESHA2011?lang=en. Accessed 1 Dec 2018.

40. World Health Organization (2019) Health systems - universal health coverage. Available at: https://www.who.int/healthsystems/universal_ health_coverage/en/. Accessed 9 Feb 2019.

41. Xu K, et al. Household catastrophic health expenditure: a multicountry analysis. Lancet. 2003;362(9378):111-7. https://doi.org/10.1016/s01406736(03)13861-5 Elsevier

\section{Publisher's Note}

Springer Nature remains neutral with regard to jurisdictional claims in published maps and institutional affiliations.

Ready to submit your research? Choose BMC and benefit from:

- fast, convenient online submission

- thorough peer review by experienced researchers in your field

- rapid publication on acceptance

- support for research data, including large and complex data types

- gold Open Access which fosters wider collaboration and increased citations

- maximum visibility for your research: over $100 \mathrm{M}$ website views per year

At $\mathrm{BMC}$, research is always in progress.

Learn more biomedcentral.com/submissions 